University of Nebraska - Lincoln

DigitalCommons@University of Nebraska - Lincoln

Civil and Environmental Engineering Faculty

Publications

Civil and Environmental Engineering

$5-2019$

\title{
Bio-desalination of brackish and seawater using halophytic algae
}

\author{
Endalkachew Sahle-Demessie
}

Ashraf Aly Hassan

Amro El Badawy

Follow this and additional works at: https://digitalcommons.unl.edu/civilengfacpub

Part of the Biomedical Engineering and Bioengineering Commons, Bioresource and Agricultural Engineering Commons, and the Civil and Environmental Engineering Commons

This Article is brought to you for free and open access by the Civil and Environmental Engineering at DigitalCommons@University of Nebraska - Lincoln. It has been accepted for inclusion in Civil and Environmental Engineering Faculty Publications by an authorized administrator of DigitalCommons@University of Nebraska Lincoln. 


\title{
Bio-desalination of brackish and seawater using halophytic algae
}

\author{
Endalkachew Sahle-Demessie ${ }^{\mathrm{a}}$, Ashraf Aly Hassan ${ }^{\mathrm{b}, *}$, Amro El Badawy $^{\mathrm{c}}$ \\ ${ }^{a}$ National Risk Management Research Laboratory, Office of Research and Development, U.S. Environmental Protection Agency, Cincinnati, OH 45268, USA \\ ${ }^{\mathrm{b}}$ United Arab Emirates University, Department of Civil \& Environmental Engineering, Al Ain, United Arab Emirates

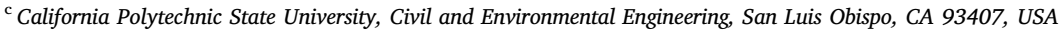

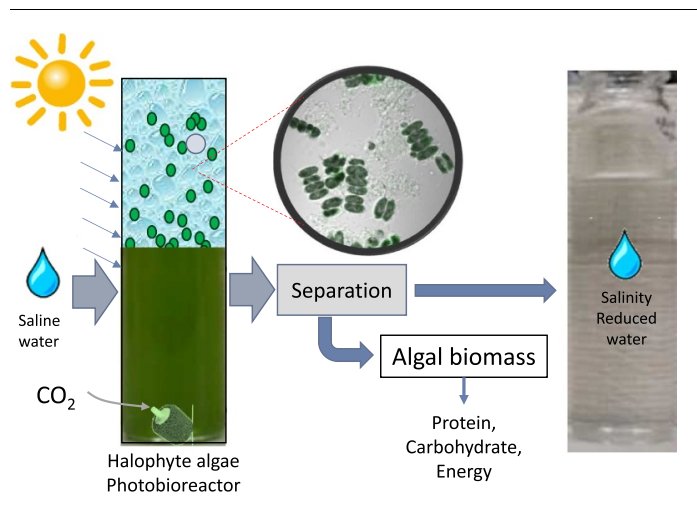

\section{A R T I C L E I N F O}

\section{Keywords:}

Bio-desalination

Halophytic algae

Brackish water

Photobioreactor

\begin{abstract}
A B S T R A C T
Global demand for water is rising. A sustainable and energy efficient approach is needed to desalinate brackish sources for agricultural and municipal water use. Genetic variation among two algae species, Scenedesmus species (S. sp.) and Chlorella vulgaris (C. vulgaris), in their tolerance and uptake of salt ( $\mathrm{NaCl}$ ) was examined for potential bio-desalination of brackish water. Salt-tolerant hyper-accumulators were evaluated in a batch photobioreactors over salinity concentration ranging from $2 \mathrm{~g} / \mathrm{L}$ to $20 \mathrm{~g} / \mathrm{L}$ and different nutrient composition for their growth rate and salt-uptake. During algae growth phase, the doubling time varied between 0.63 and 1.81 days for $S$. sp. and 3.1 to 5.9 for $C$. vulgaris. The initial salt-uptake followed pseudo first order kinetics where the rate constant ranged between -3.58 and -7.68 day $^{-1}$ reaching up to $30 \%$ in a single cycle. The halophyte algae $S$. sp. and $C$. vulgaris that were selected for pilot-scale studies here represent a promising new method for desalination of brackish waters. Halophytic technologies combined with the potential use of algae for biofuel, which offsets energy demand, can provide a sustainable solution for clean, affordable water and energy.
\end{abstract}

\section{Introduction}

The rapid growth of population, the increase in per capita consumption, and the fast growth of urbanization are creating critical water demand. The challenge of providing clean water is on the rise
$[1,2]$. New water-recovery technologies and improving the water communities' infrastructure can partly alleviate the need. However, these approaches require long-term investments and many developing countries are facing increasing chronic water problems [3]. Thus, there is a need to improve available water resources at affordable costs to

\footnotetext{
* Corresponding author.

E-mail address: alyhassan@uaeu.ac.ae (A. Aly Hassan).
} 
support urban, rural and agricultural prosperity, and protecting the environment.

Desalination of brackish groundwater and seawater could unlock the vast water resource and provide a sustainable source of water to water-stressed regions of the world. Thermal distillation and membrane separation account for $33 \%$ and $53 \%$ of the global utilization, respectively [4]. However, the current desalination technologies consume large amounts of energy (4-8 $\mathrm{kWh}$ of electrical power per $\mathrm{m}^{3}$ treated water) and require high capital investment. The state-of-the-art reverse osmosis technology is reaching the thermodynamic limit in the energy demand [4]. The cost of water produced by desalination is 3 to 5 times the water produced from conventional sources [4], and the technology has yet to prove its viability in providing water beyond household purposes and a few strategic industries at a reasonable price. Thus, the supply of water from current desalination technologies to agriculture may not achieve food security due to logistical, financial and environmental problems [5]. This was still debated during the recent drought in California [6]. The environmental impact of desalination technologies stems from 1) the high thermoelectric use resulting in an emission of more than $1.8 \mathrm{~kg} \mathrm{CO}_{2} / \mathrm{m}^{3}$ and 2) discharge of concentrated brine to the aquatic environment $[7,8]$. Therefore, there must be a paradigm shift that requires other approaches.

Halophytic plants thrive in environments with high salt concentrations. Some halophile algae are not only salt tolerant but can concentrate multiple times more salt levels than the water they live in [13]. Plants and algae that occupy estuaries and saline interior regions that have high salinity habitats along salt and brackish marshes may undergo significant selections for the capability to tolerate salt. This large pool of plant and algae provides many candidates for use in engineered, biotechnology systems intended to treat saline water $[9,10]$. Although halophyte plants are proven to remove salt from saline soils effectively [9], the data on their use for treatment of saline water is scarce. The concept of bio-desalination is novel, and research is still in its infancy. Macrophyte algae sequester salts in their frames and remove them from solution [11]. The algae, cf. Pheridia tenuis, have shown to sequester salt within the vacuoles of its tissues and convert the water to salt-free if it is left to grow in a bucket that contained seawater [9]. The uptake of salts by halophyte represents the condition wherein the salt is accumulated against an increasing osmotic gradient.

El-Sayed et al. [12] evaluated the growth of, Scenedesmus sp. (S. sp.), and reported grow favorably and complete their life cycle even under full salinity level (35 g/L) and the algae removed at least $25 \%$ of the total salt. Duckweed in detention ponds tolerate salinity and adapt with time to high salinity and have shown to reduce up to $25 \%$ of the salinity of the water irrespective of the initial salinity [13]. In a previous study, S. obliquus was grown in different salinities [14]. As the salinity of the water increased the desalination rate and the removal of $\mathrm{NaCl}$ increased significantly. Salinity removal of up to $30 \%$ was reported after 16 days of incubation. Samples were centrifuged, filtered and then measured for total dissolved solids. Another study reported similar cation uptake at salinities up to 25 using $S$. obliquus [15]. The reduction of $\mathrm{Na}^{+}$reached optimum levels $(6.62 \mathrm{mg} / \mathrm{L})$ at carbonate alkalinity of $35 \mathrm{mmol} / \mathrm{L}$. Salinity stress intensified with increased concentrations of $\mathrm{Na}^{+}$for $S$. obliquus, while it decreased significantly with higher concentrations of $\mathrm{K}^{+}, \mathrm{Ca}^{2+}$ and $\mathrm{Mg}^{2+}$.

Other algal species were shown to have the potential for biological desalination [16]. Thirty-one shrimp ponds in areas of southern Thailand were sampled, and purple non-sulfur bacteria (NW16 and KMS24) were isolated and investigated for bioremediation potential. Salinity removal of $30 \%$ was achieved together with other heavy metals [16]. A team of researchers evaluated the use of cyanobacteria for the removal of sodium chloride from seawater [17]. Two Euryhaline strains, one of freshwater (Synechocystis sp. Strain PCC 6803) and one of marine origin (Synechococcus sp. Strain PCC 7002) were identified as possible candidates. Genetic modifications increased the bioaccumulation capacity of $\mathrm{Cl}^{-}$in both strains. A thermodynamically favorable approach of growing cyanobacteria may be the use of just sufficient light and nutrients for rapid growth while letting each cell enough energy (in the form of sugars) to counteract the stress exerted by salt. Researchers studied a dozen heterogeneous strains of euryhaline bacterial to determine whether salt-tolerant bacteria have common characteristics that relate to both their taxonomy and the mechanism of salt tolerance, concluded that these organisms are probably separate species of the same genus [18].

A pilot scale study was conducted in Egypt to evaluate the utilization of algae ponds in brine desalination [19]. Algae (S. sp.) was grown under saline conditions and then introduced to a saline basin at a rate of $0.4 \mathrm{~L} /$ basin/run, while growth media (BG-11) was supplied at a $0.1 \mathrm{~L} /$ basin/run. The volume of the basin was not mentioned in the article; however, it was estimated at 4201 based on the analysis of the image presented in the article. The total dissolved solids concentration in the tank ranged from $40 \mathrm{~g} / \mathrm{L}$ to $80 \mathrm{~g} / \mathrm{L}$. It was reported that the system achieves high removal for salinity between $13 \%$ (for day one) to $63 \%$ (for day six) and the removal efficiency increases with the increased salinity.

In this study, halophile algae (S. sp. and Chlorella vulgaris (C. vulgaris)) were grown in photobioreactor (PBR) under carefully controlled conditions to sequester $\mathrm{NaCl}$ salt from brackish and seawater, and their potential use for biological desalination was evaluated. The biological mechanism and the factors affecting the reduction of salinity were investigated. $\mathrm{CO}_{2}$ was utilized for the growth of algae, and valuable lipids were harvested from algae as a byproduct that can be used to generate bio-fuel and supply energy back to the desalination process. The growth rate of algae and the rate of salt uptake from seawater and brackish water were measured. The impact of algae regrowth on salinity removal was also investigated in a continuously stirred PBR with a filtration loop to maintain constant levels of algae in the PBR. Finally, we explored the performance of a $60 \mathrm{~L}$ PBR scaled-up system that has with a filtration system in a recycle loop.

\section{Materials and methods}

\subsection{Materials}

The plan for the algal screening and bio-desalination study is summarized in Fig. S1 (Supplemental information).

\subsubsection{Algae}

Pure algae species samples were acquired from Culture Collection of Algae at the University of Texas, Austin (UTEX). The cultures were grown in a culture chamber at a temperature of $25^{\circ} \mathrm{C}$, a light intensity of $40 \mu \mathrm{mol} \mathrm{m}^{2} \mathrm{~s}^{-1}$ and $16 / 8 \mathrm{~h}$ day/night cycle. Inoculation cell density of the cultures was reached by placing them in a stirred incubator for two days at a constant light intensity of $280 \mu \mathrm{mol} \mathrm{m}^{2} \mathrm{~s}^{-1}$ and headspace enriched with $0.5-5 \%$ carbon dioxide. All cultures were observed under an optical microscope for identification of species' contamination. Despite the fact that $C$. vulgaris is often found in freshwater, it is shown that it could resist salinity up to $20 \mathrm{~g} / \mathrm{L} \mathrm{NaCl}$ [20] while no growth was observed at $30 \mathrm{~g} / \mathrm{L} \mathrm{NaCl}$. Two commercial and a laboratory synthesized growth media including F/2 (Kent Marine), Alga-Gro (Carolina Inc.), and Biofilter-Media (BM) that was used earlier for growing aerobic bacteria in a biofilter [21,22]. The cations concentration and percentage found in these growth media and artificial seawater "Instant Ocean" are shown in Table S1. The nutrients added to the growth media accounts for less than $3 \%$ of the total ions found in the saltwater. For every liter of brackish water $20 \mathrm{~mL}$, Alga-Gro was added, that contained $8 \mathrm{ppm}$ of $\mathrm{Na}^{+}$ion.

\subsubsection{Preparing typical seawater}

Artificial seawater was prepared by dissolving mixed salts of known composition in deionized water. The ASTM Standard D1141-98 method (Table S2) has the advantage of being entirely chemically defined, 
reproducible and follows. However, preparing a solution, multiple components can be laborious and may not support satisfactory algal growth. Commercial salt mix, Instant Ocean, was used to for an artificial sea water that contained most of the major, minor, and trace elements necessary for marine life. The salinity of Instant Ocean was compared with water containing $\mathrm{NaCl}$.

\subsubsection{Nutrients}

The algal culture media were prepared based on simulated seawater supplemented with nutrients such as N, P, trace elements and vitamins, depending upon the requirements of each species (Table S1). Physical factors such as $\mathrm{pH}$ and temperature were carefully controlled during algal growth. Three growth media use for this study contain nitrate concentration of 9, 47 and $283 \mathrm{ppm}$ for Alga-Gro, F/2, and BM, respectively. The $\mathrm{BM}$ has the necessary growth elements: $\mathrm{B}^{+3}, \mathrm{Ca}^{+2}, \mathrm{Cl}^{-}$, $\mathrm{Co}^{+2}, \mathrm{Cu}^{+2}, \mathrm{Fe}^{+3}, \mathrm{~K}^{+}, \mathrm{Mg}^{+2}, \mathrm{Mn}^{+2}, \mathrm{Mo}^{+6}, \mathrm{NH}_{4}{ }^{-}, \mathrm{Na}^{+}, \mathrm{SO}_{4}{ }^{-2}, \mathrm{Zn}^{+2}$, p-Aminobenzoic acid, Biotin, Thiamin Hydrochloride, Cyanocobalamin, Folic Acid, Nicotinic Acid, Riboflavin, Pantothenic acid, pyridoxine hydrochloride, and Thioctic Acid; in addition to a nutrient spike solution of $2 \mathrm{M} \mathrm{NaNO}_{3}$ and $0.22 \mathrm{M} \mathrm{NaH}_{2} \mathrm{PO}_{4} \cdot \mathrm{H}_{2} \mathrm{O} . \mathrm{F} / 2$ is similar into the composition of the $\mathrm{BM}$, but it is missing $\mathrm{B}^{+3}, \mathrm{Ca}^{+2}, \mathrm{~K}^{+}$, and $\mathrm{Mg}^{+2}$. In addition, the vitamins available within the $\mathrm{F} / 2$ are very limited namely, vitamin $\mathrm{H}, \mathrm{B}_{1}$ and $\mathrm{B}_{12}$ (Tables S3 and S4). The type of growth media and salt concentration modulate the $\mathrm{pH}$ of the solution (Table S5).

\subsubsection{Screening tests}

Algae were grown in a temperature controlled PBRs that were kept at $25^{\circ} \mathrm{C}$ under $18 / 6 \mathrm{~h}$ fluorescent light cycle (Fig. S2). Air enriched with $0.5-5 \% \mathrm{CO}_{2}$ was humidified in autoclaved deionized water and bubbled in tightly closed $250 \mathrm{~mL}$ and $500 \mathrm{~mL}$ bottles equipped with a vent. Different levels of salinity were achieved by adding either synthetic seawater (Instant Ocean Co.) or sodium chloride (Fischer Scientific) to produce the desired salinity. Algae were grown in salt water with salinity levels varying from brackish water to salt water ( 2 to $20 \mathrm{mg} / \mathrm{L}$ of $\mathrm{NaCl}$ ) and with three types of growth media nutrients.

\subsubsection{Variation in carbon dioxide}

The depletion of $\mathrm{CO}_{2}$ in dense cultures was reduced by bubbling with air and increased $\mathrm{CO}_{2}$ concentrations (0.5-5\%). Pure $\mathrm{CO}_{2}$ was supplied through Praxair ${ }^{\circledast}$ compressed tanks fitted with a $\mathrm{CONCOA}^{\circledR}$ high purity regulator. The amount of $\mathrm{CO}_{2}$ injected is controlled by a $\mathrm{pH}$ probe with an internal temperature compensation. The PBR maintained at temperature for the microalgae growth. The air and $\mathrm{CO}_{2}$ streams were first passed through inline $0.2 \mathrm{~mm}$ filter units (e.g., Millipore Millex GS) to maintain sterile conditions. Compressed air was used through a centrally housed system to obtain a desired gas mixture ratio. The two sources of gas were connected to a Cole Parmer ${ }^{\circledR}$ gas proportioner flow meter. According to the desired $\mathrm{CO}_{2}$ concentration, the gas flow of house air and the compressed $\mathrm{CO}_{2}$ were adjusted and setting the mass flow controller. However, unless there is a large amount of biomass taking up the $\mathrm{CO}_{2}$, the higher concentrations could cause a significant decline in $\mathrm{pH}$. The batch tests were run in duplicates, and some of the optical density measurements were made at 1:5 dilutions for full bloom samples.

A scaled up PBR was operated in closed container-based systems of cylindrical photobioreactor $(1.8 \mathrm{~m}$ long, $20.3 \mathrm{~cm}$ diameter, a volume of 601 ) with a recycle with the rate of recycling of $27 \mathrm{~L} / \mathrm{min}$ for successful algae growth and desalination. A circular light at the top of the cylindrical reactor (Red and blue $90 \mathrm{~W}$ LEDs that has the spectrum of light, $630 \mathrm{~nm}, 460 \mathrm{~nm}$ and an output $3800 \mathrm{~lm}$ ) provided the best illumination for the recycle reactor operation. For the pilot-scale system, multiple water quality monitoring sensors (YSI Yellow Springs, OH, USA) were used for daily monitoring of the reactor including dissolved oxygen, conductivity, temperature, turbidity, chlorophyll, $\mathrm{pH}$, and an oxidation reduction potential.

\subsection{Measuring algal growth}

A set of 20 PBRs were continuously aerated and aliquots were withdrawn daily from the PBRs and portions were centrifuged, and the supernatant liquid was analyzed for $\mathrm{NaCl}$ and conductivity to determine the concentration between the cell and suspending liquid. Basic cell culture management procedures, such as aseptic techniques and minimizing aerosol contamination were implemented to avoid cross-contamination. Samples were collected in a test tube from PBR and various measurements were made before they were returned to the PBR bottles. Algal growth was measured using the change in turbidity (Hatch 2100), chlorophyll (YSI 6025 chlorophyll sensor) and microscopic cell count of microalgae (Nikon E600).

Conductivity was measured using two cell conductivity meters (Accumet AB150) without dilutions, and the probe was recalibrated when the standard measurements deviated more than $5 \%$. Nitrate ions and $\mathrm{pH}$ were measured using probes (Accumet). Sodium concentration was also determined using ICP-OES; liquid samples were analyzed after filtration through $0.2 \mu \mathrm{m}$ filter while solid samples were extracted from the filter and acid digested using nitric acid. Chlorophyll concentration was determined by detecting the fluorescence in situ probe with the YSI 6025 Chlorophyll sensor. Algal growth was monitored at an equal time interval using a visible-light spectrometer at $\lambda=730 \mathrm{~nm}$ to track the density of the algal cells. These species were tested under varying process conditions in finding their salt tolerance, growth rate, and salt uptake.

\subsection{Measuring waster salinity and salt uptake}

The standard method for measuring primary and secondary anions according to U.S. Environmental Protection Agency (EPA) Method 300.0 is the use of ion chromatography (IC) [23]. Salinity can also be measured to be directly proportional to the amount of chlorine in brackish and seawater, and because chlorine can be measured accurately by simple chemical analysis. Chloride probes salinity is measures based on chlorinity of the water. Conductivity meter can also measure salinity very precisely and relatively easy to use compared with the chemical techniques used to measure the chlorinity. Thus, electrical conductivity is one of the necessary parameters of water quality detection in the seawater desalination. Conductivity measures salinity of the water as a function of chlorinity relative to standard seawater, thus the two approaches are similar [24]. In this study, electrical conductivity and chlorinity were the primary approaches for tracking the extent of desalination.

\section{Results}

\subsection{Initial assessment of algae growth}

The initial batch experiments were aimed to explore the differences in algae growth and salinity reductions based on the type and concentration of growth media used. The influence of the three types of growth media BM, F/2 and Alga-Gro for growth-nutrients was compared at selected levels of initial salt concentrations using either Instant Ocean or pure $\mathrm{NaCl}$. The goal was to successfully acclimate the algae depending on ambient concentrations and length of the exposure. During the acclimation stage, the algae underwent a multistage process that included the readjustment of ionic and osmotic potentials as well as broader physiological changes, including turgor adjustment in response to salt stress [25]. Amezaga et al. [26], have proposed a possible mechanism for bio-desalination using photosynthetic bacteria. The chemical energy carrier, ATP, powers $\mathrm{Na}^{+}$export from cells either directly or indirect means by $\mathrm{Na}^{+}$-pumping ATPases or $\mathrm{H}^{+}$-ATPases [27]. Environmental manipulations after the growth phase would halt $\mathrm{Na}^{+}$ export, and light energy is used to absorb $\mathrm{Cl}^{-}$by halorhodopsin. The result of chloride in the cell is drawing $\mathrm{Na}^{+}$through permeable channel 

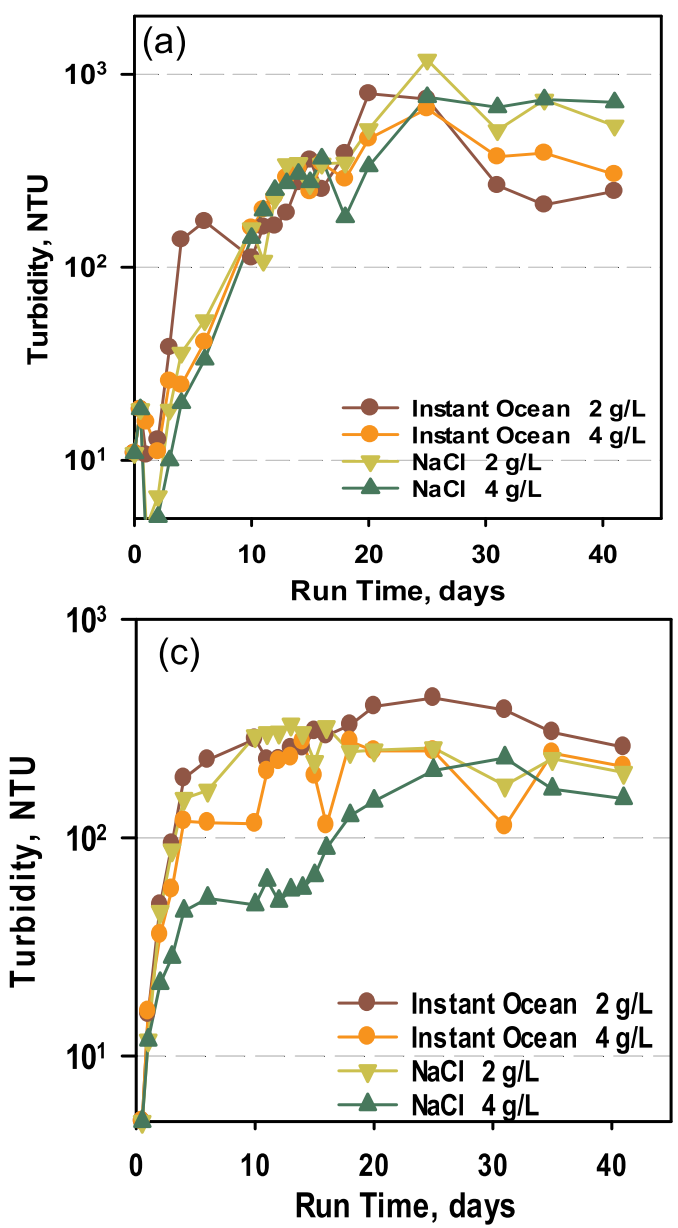
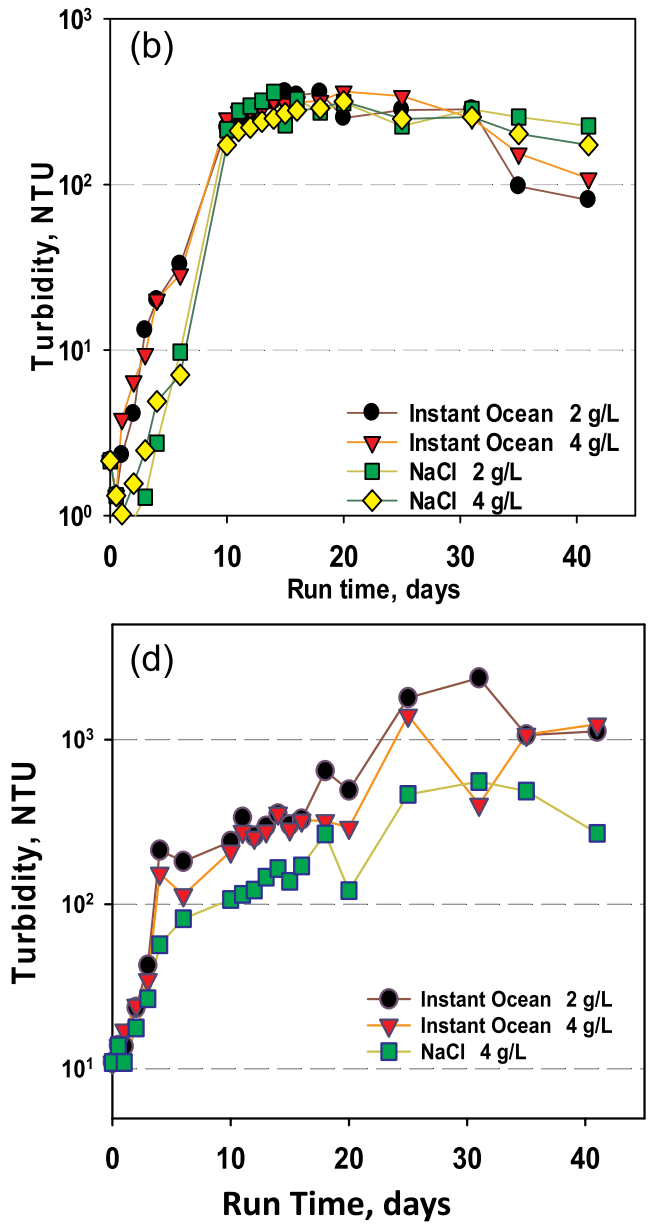

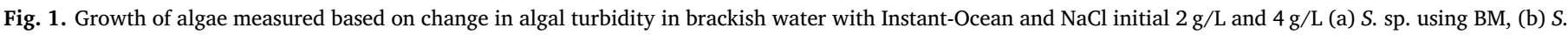
sp. using F/2 Media, and (c) C.C. vulgaris using F/2 growth media, (d) C.C. vulgaris BM.

proteins [26].

The growth of algae was monitored based on the changes of turbidity over 40 days. Fig. 1 shows the growth of $S$. sp. and C. vulgaris in different saltwater, dissolving either "Instant Ocean" or $\mathrm{NaCl}$, at selected concentrations of $2 \mathrm{~g} / \mathrm{L}$ and $4 \mathrm{~g} / \mathrm{L}$, and two growth media. The growth rate was influenced by the type of nutrients where the rate of growth followed the order BM $>$ F/2 $>$ Alga-Gro (Fig. S3). Since Alga-Gro failed to show adequate algal growth in these initial tests, it was removed from further analyses, and the results are not shown in Fig. 1. This comparison is even more apparent based on chlorophyll concentration, where the algae in BM turned dark green and can be distinguished by the naked eye (Fig. 2). The effects of growth media were more significant at higher salt concentrations of 10 and $20 \mathrm{~g} / \mathrm{L}$ than at concentrations less than $4 \mathrm{~g} / \mathrm{L}$, where the BM showed superior growth compared to $\mathrm{F} / 2$. $S$. sp. showed low growth rates at a salt concentration of $10 \mathrm{~g} / \mathrm{L}$ using $\mathrm{F} / 2$, while growth was not affected by an initial concentration of $20 \mathrm{~g} / \mathrm{L}$ salt using the BM. Additionally, $S$. sp. showed superior growth rates compared to $C$. vulgaris. This became more apparent at higher salt concentrations. $C$. vulgaris growing at the salt concentration of $10 \mathrm{~g} / \mathrm{L}$ showed low growth rates. The influence of ions available in biomass is shown and growth media are shown in Figs. S3 and S4 (Supplemental Information).

The $\mathrm{pH}$ increased slightly with time regulating growth and causing some fluctuation and lack of reproducibility. The growth nutrients added influenced the solution $\mathrm{pH}$ value with the BM showing the highest $\mathrm{pH}$ at 8.7 for both algal species (Table S5). Both Alga-Gro and the $\mathrm{F} / 2$ media showed an average $\mathrm{pH}$ below 8 . On the other hand, the $\mathrm{BM}$ media has buffering effect even with $\mathrm{CO}_{2}$ enriched air that lowers the water $\mathrm{pH}$.

\subsection{Kinetics of algal growth and salt uptake in a batch Photobioreactor}

Algal growth is autocatalytic process such that the rate of growth is proportional to the cell concentration already present. A general form of the growth equation is as follows:

$\mu\left(\right.$ day $\left.^{-1}\right)=\frac{\ln X_{2}-\ln X_{1}}{t_{2}-t_{1}}$

$X_{1}$ and $X_{2}$ are optical densities at time $t_{1}$ and $t_{2}$, and $\mu$ is the instantaneous rate of increase [28]. This growth rate constant varied for the different types of algae, type of nutrients used, and the initial salt concentration. For $C$. vulgaris the specific growth rate during the growth phase varied from 0.07 to 0.21 per day that corresponded to doubling time of 3.1 to 5.9 days. The growth rate of $S$. sp. was higher than that of $C$. vulgaris. For $S$. sp. the specific growth rate during the growth phase varied between 0.63 and 1.82 per day that corresponds to double time in the range of 0.42 and 1.2 days depending on the nutrient and salinity. The highest specific growth rate was observed during the growing of $S$. sp. at a low salt concentration of $2 \mathrm{~g} / \mathrm{L}$ of Instant Ocean, while the lowest occurred for $C$. vulgaris growing in a water solution of initial $\mathrm{NaCl}$ of $4 \mathrm{~g} / \mathrm{L}$.

\subsection{Bioaccumulation and biosorption of $\mathrm{NaCl}$ in algal cells}

There are many cellular functions such as nutrient uptake, photosynthesis, $\mathrm{pH}$ homeostasis in an alkaline environment and nitrate 

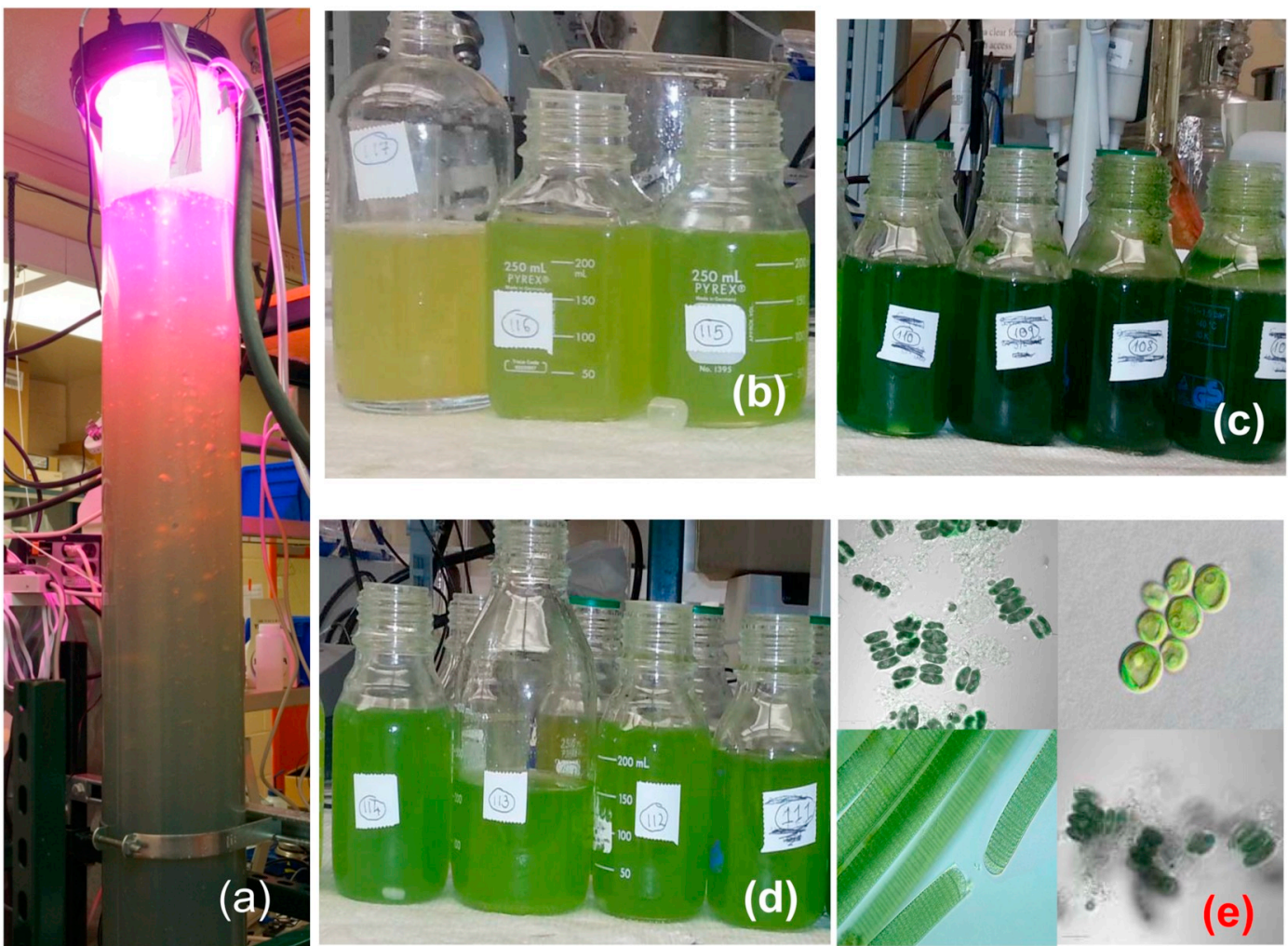

Fig. 2. Biodesalination experimental system using S.S. sp. (a) a column PBR, (b) PBR of Alga-Gro media, (c) PBR of BM (d) PBR of F/2 growth media, (e) Microscopic images of Halophytes Species Tested (UTEX Culture collection of Algae).

assimilation that necessitate some $\mathrm{Na}^{+}$[29-31]. However, high levels of $\mathrm{Na}^{+}$concentrations can destabilize fatty acids in the cell membrane and halt photo-autotrophic growth [32]. The level of sodium ion depends on the strains of algae. The higher salt concentrations created unfavorable growth conditions in algae. The increase in external concentrations of ions impairs the osmotic balance of the cells and their surrounding and forces exosmosis from the cell. Exosmosis leads to the loss of turgor pressure and tightens the influx of ions into the cells according to their electrochemical gradients $[25,26]$. The algae acclimation proceeds to salt-tolerance and gradually leads to steady-state growth.

The acclimation of algae to high salinity may include three basal processes: restoration of turgor, regulation of the uptake and export of ions through the cell membranes, and induction of the accumulation of photosynthetically produced osmoprotective "compatible" solutes such as glycerol, and stress proteins. The influx of $\mathrm{NaCl}$ could disrupt the cellular homeostasis and impair the function of biopolymers. The algae acclimation could involve uptake and export of $\mathrm{Na}^{+}$and $\mathrm{K}^{+}$using redox-driven $\mathrm{Na}^{+}$pump [27,29], for example, Dunaliella salina [30] accumulates protective compatible solutes and proteins [31,32], or intercellular ion compartmentalization in the vacuole of the cell. If $\mathrm{Na}^{+}$ and $\mathrm{Cl}^{-}$are sequestered in the vacuole of an algae cell, $\mathrm{K}^{+}$and organic chemicals, such as proline and glycine would accumulate in the cytoplasm of algae to balance the osmotic pressure [33]. Ahmad and Hellebust [34], suggested salt is accumulated within the cell for the species of $C$. autotrophica to regulate the osmotic pressure.

Removal of salinity was observed based on conductivity measurements for $S$. sp. and $C$. vulgaris species and all media types. As explained above, despite their salt tolerance and sufficient growth, the considerable variation in salt uptake of the halophytic algae could be as the result of their adaptation mechanism to salinity. As the concentrations of $\mathrm{Na}^{+}$and $\mathrm{Cl}^{-}$accumulated in the vacuole of the cells reach above $200 \mathrm{mM}$, and these concentrations could inhibit enzyme activities in the cytoplasm. However, obtaining direct experimental evidence for the compartmentation of salts in halophytic algae is technically challenging even with X-ray microanalysis.

Bioaccumulation and biosorption happen in most living organisms [35]. Metabolic absorption of salts in biological systems is a spontaneous process, where bioabsorption is thermodynamically favored and requires no energy. The amount ion that a solid adsorbent can remove from a solution is dependent on kinetics of the equilibrium and the composition of the sorbents cellular surface [36]. The adsorption of ionic contaminants onto a cellular structure could result in bioaccumulation that is a metabolic aerobic process that is driven by energy from a living organism [36,37]. Microalgae can remove metal ions from water by either biosorption or bioaccumulation [38-40]. The cell wall of algae is mainly comprised of proteins, polysaccharides, and lipids. The cell wall is also negatively charged and sticky that allows it to absorb cations [38]. The mechanisms that algae absorb cations include surface deposition, physical and biosorption, active transport, and passive diffusion [41]. However, the primary channel through which about $80 \%$ of cations are absorbed is biosorption.

\subsection{Endogenous salt uptake in algae}

Fig. 3 summarizes all the preliminary salt removal experiments with S. sp. and C. vulgaris from the initial salt concentration $4 \mathrm{~g} / \mathrm{L}$. Results show the minimal difference in salinity removal between both species. $S$. sp. showed average higher removal rates. Both species underwent a phase of salinity decline initially until day 16 . The following conductivity measurement at day 18 shows an increase in salinity, followed by another phase of salinity decline. The first drop occurred during the growth phase, while the second phase occurred during the stagnant phase. The growth phase salt uptake had a steeper slope than the stagnant phase salt uptake marking an initial high salt uptake. These results suggest that salt is used in cellular uptake is mainly due to bioaccumulation and the salt uptake was not merely a function of the number of cells. Salinity reduction increased when the generation of 


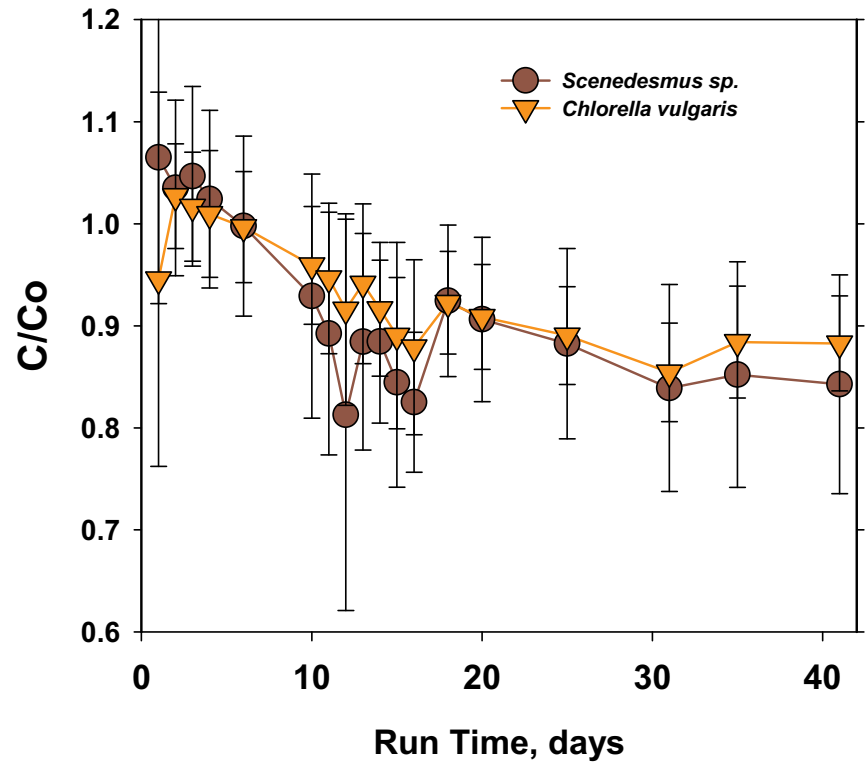

Fig. 3. Reduction of normalized conductivity for $S$. sp. and $C$. vulgaris grown at selected conditions where the $\mathrm{C} / \mathrm{Co}$ is shown using BM growth media, at initial salt concentration, $4 \mathrm{~g} / \mathrm{L}$.

new cells was much higher than cells lost. The slope in Fig. 3 during the stagnant phase suggests that a fraction of the salt uptake is due to biosorption or the amount of salt released from dead cells is less than the amount taken up in forming new cells. However, the increase in salt concentration at day 18 marking the end of the growth phase is probably due to a sudden increase in the number of dead cells resulting salt release out of algal. This suggests the process is biosorption.

The rate of salt uptake during the growth phase of the algae was estimated using first order kinetics model:

$\ln \frac{C}{C_{o}}=k t$

where $C_{o}$ and $C$ are concentrations of salt originally and at time, t.

The initial salt uptake rate for $S$. sp. varied between -0.015 to $0.0358\left(\right.$ day $^{-1}$ ) depending on the nutrient type and initial salt concentrations (Fig. S4). Two distinct regions could be found in the relationship, the salt uptake part which corresponds to the algal growth phase and the salt release part which corresponds to the algal stationary phase. As the name of both phases suggests, there is a high rate of salt uptake in the growth phase, while very mild release occurs in the stationary phase.

Fig. 3 shows the effect of growth nutrients, salt type, and initial concentration on the reduction of salt concentration in the bulk phase. The growth of algae and removal of salinity was modulated by the growth media and the initial levels of salt. Salinity reduction up to $30 \%$ was observed using $S$. sp. grown in BM as seen in Fig. 4a. The salinity removal for this alga in other test media was less than this value. The second highest removal amount (26\%) was observed with the C. vulgaris grown in BM as well. Comparable salt up-take was observed for both algal species in the BM which indicated favorable algal growth conditions are the main factor that determines the extent of salt removal. The presence of salt lowers the activity of $\mathrm{Ca}^{2+}$. However, the BM allowed faster growth rate that resulted the higher desalination rate could be attributed to the fact that increased concentration of $\mathrm{Ca}^{2+}$ in $\mathrm{BM}$ solution countered the possibility of a NaCl-induced $\mathrm{Ca}^{2+}$ deficiency in the cells. The chlorophyll content of $C$. vulgaris increased in selected media in the following order: Alga-Grow $<\mathrm{F} / 2<\mathrm{BM}$. The low chlorophyll indicates that the salt stress and nutrient deficiency limited the algae to spend excessive energy for the synthesis of lots of new chlorophyll molecules and binding proteins (Fig. S5). Fig. 4b.
Highlights the importance of the contribution of other ions in salinity reduction, where the salinity of both algae species at both initial concentrations of 2 and $4 \mathrm{~g} / \mathrm{L}$ using Instant Ocean and $\mathrm{NaCl}$ salts are presented. Instant Ocean showed significantly higher salinity removal rates with a more significant margin at $S$. sp. compare to $C$. vulgaris. The results in Fig. 4c shows that the difference in algae salt uptake between the $2 \mathrm{~g} / \mathrm{L}$ and $4 \mathrm{~g} / \mathrm{L}$ solutions were insignificant. Prescreening of algal growth media for strain selection and the effects of different media on the performance of algal-cultural under laboratory conditions is shown in Fig. 5.

\subsection{Algae regrowth in a recycled media}

The initial growth and salinity measurements suggested that dead cells release absorbed salt back to the solution. Therefore, it is essential to avoid subjecting the solution to the decline phase. Salinity removal was evaluated for both at $S$. sp. at $4 \mathrm{~g} / \mathrm{L}$ for F/2 and BM, $S$. sp. at $20 \mathrm{~g} / \mathrm{L}$ $\mathrm{BM}$, and $C$. vulgaris at $4 \mathrm{~g} / \mathrm{L}$ for both $\mathrm{F} / 2$ and $\mathrm{BM}$. Algae underwent the growth, stagnant phase, and started the decline phase. Results are shown in Fig. 5a. On day 35 after inoculation, all of the solution was centrifuged at $5000 \mathrm{rpm}$ for $30 \mathrm{~min}$. The concentrate was removed, and it was then subjected again to the test conditions, where the growth nutrients were added to the concentrate similarly to the starting conditions. The effects of growth nutrients differ depending on the type of media, where $\mathrm{F} / 2$ media lead to a sharp increase in growth reaching the peak at day 45 for $S$. sp. and day 55 for $C$. vulgaris. However, a short growth peak was followed by immediate sharp decline. BM showed different pattern. While the initial growth before day 35 was average the regrowth rate only led to an increase in growth forward. The growth in some cases was double the initial growth indicating the algae growth was successful in most of the test replicas. Regrowth was not observed in one of the $S$. sp. with $\mathrm{F} / 2$ triplicates while it was successful in the other two bottles.

Salinity removal is presented in Fig. 5b. Salt removal followed very similar pattern to the initial results presented in Fig. 3. In the first 20 days, salinity removal up to $15 \%$ was observed. Salinity was increased again around day 25 and it kept decreasing constantly throughout the duration of the experiment. While the $4 \mathrm{~g} / \mathrm{L}$ experiments showed relatively close margins in performance, the $20 \mathrm{~g} / \mathrm{L}$ didn't show any salt removal until day 50 . The maximum salt removal at $20 \mathrm{~g} / \mathrm{L}$ salt was $3 \%$.

\subsection{Flow reactor with recirculation and system upscaling}

Previous results have shown that the best salt removal was obtained during the growth phase. Therefore, a method was devised to continuously filter out algae from the photobioreactor system. A two liter PBR was seeded with $S$. sp. using BM for growth. The reactor was fitted with a recirculation pump and the flow was forced through a course filter paper that operated a rate of $2 \mathrm{~L} / \mathrm{min}$. The filter removed larger and aggregated cells and was replaced every other day. This PBR was operated for a period of 3 months without the need to reseed. A schematic of the setup and profile of the concentration decline is presented in Fig. 6 . The salt concentration was declining steadily till day 40 reaching $32 \%$ removal with an unexplained peak that occurred for few days (14-17). After day 40 the salt concentration was almost constant with a maximum removal observed of $36 \%$ at day 85 . This system shows that a continuous separation of algae works as well as regrowth in the same media. Both concepts showed superior performance suggesting that a mechanism of continuous algae removal from solution is a key to success of this process. The performance of a three-stage desalination process, based on the single growth cycle removal, is shown in Fig. S7.

Scaling-up the process to a 10-gallon (35 L) tank was unsuccessful for both types of algae $S$. sp. and C. vulgaris. Algae was left to grow at a salt concentration of $10 \mathrm{~g} / \mathrm{L}$ for 4 months. However, blooming was not 


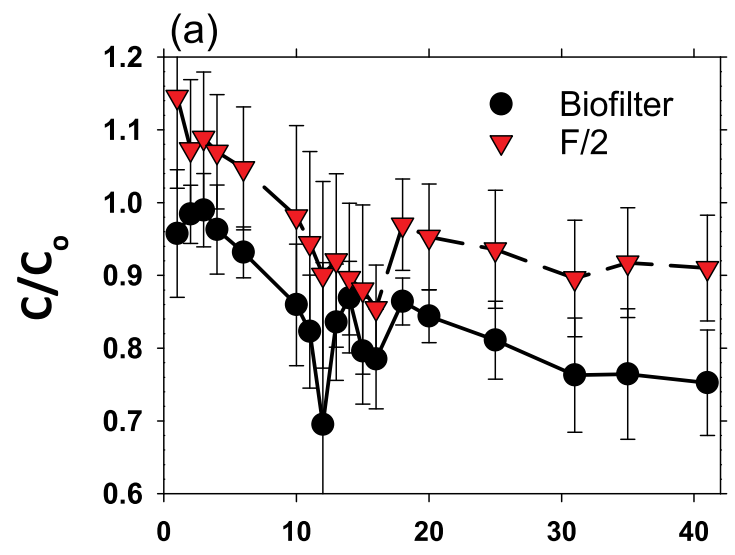

(c)

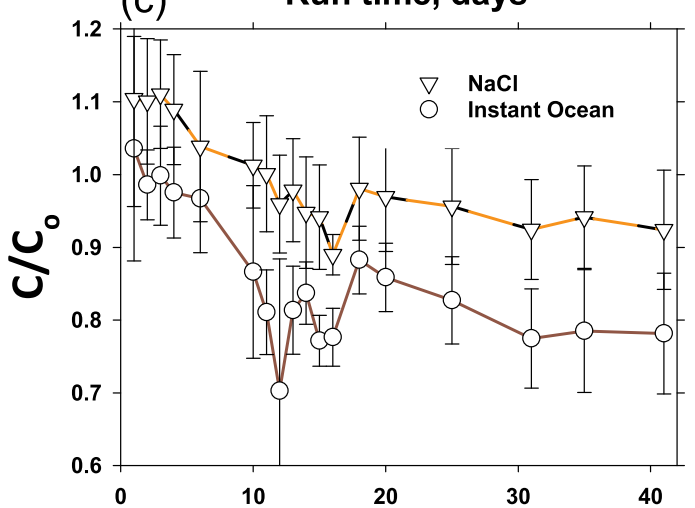

(e)

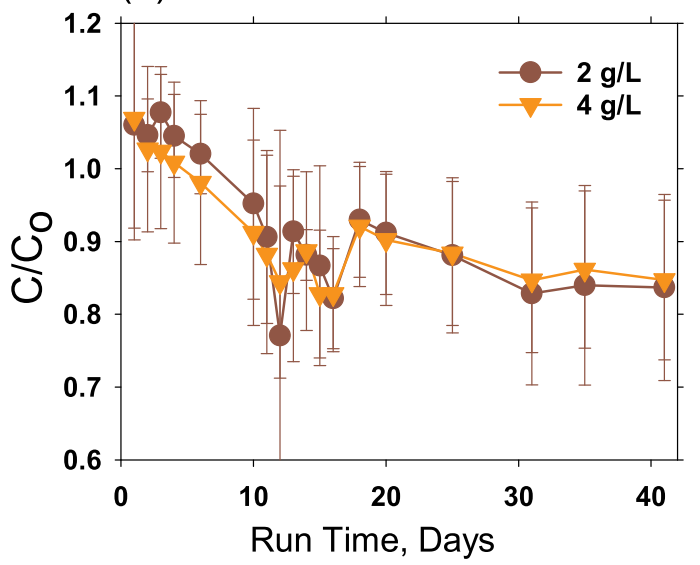

(b)

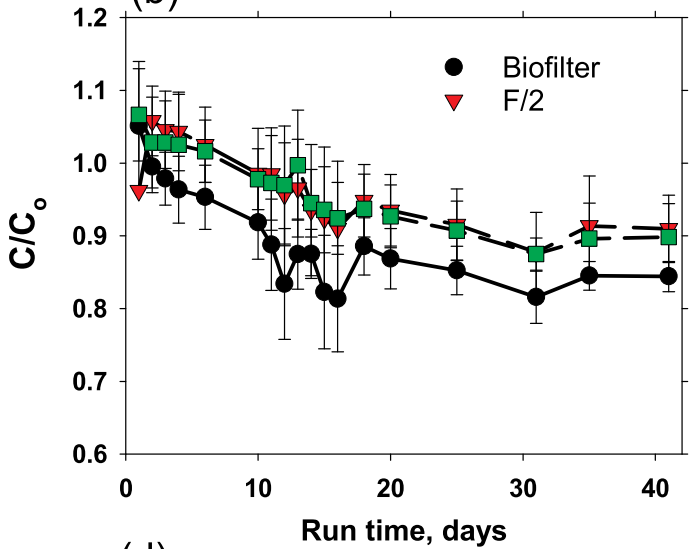

(d)

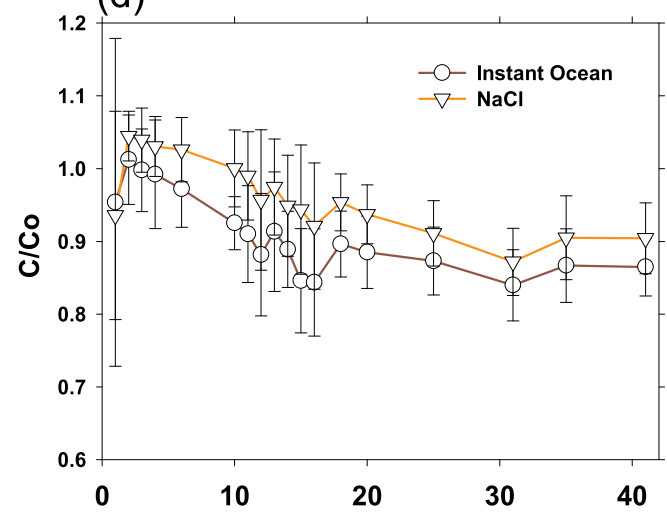

(f) Run time, days

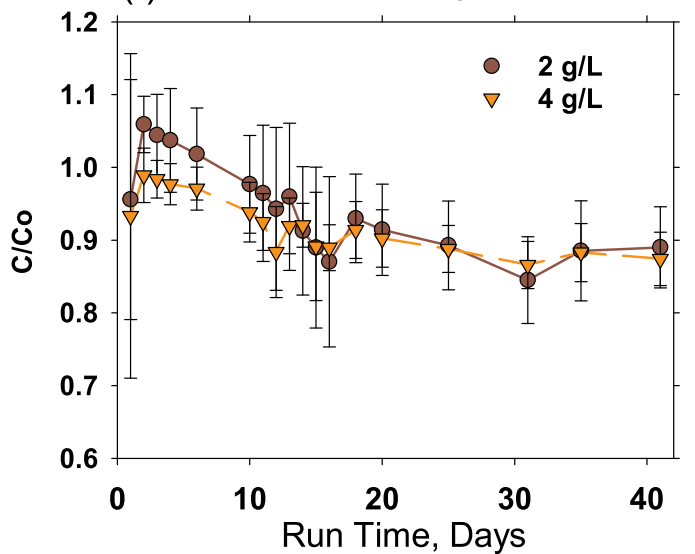

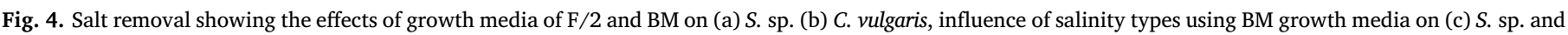
C. vulgaris, and the effects of initial concentration (d) S. sp. and C. vulgaris.

achieved in this larger volume. The salt concentration did not register significant change during this period for both species. This was mainly due to inadequate penetration of light within the aquarium.

\subsection{Effect of algae on dissolved other ions}

Salinity were measured based on the water conductivity and confirmed based on elemental analysis using Inductively coupled plasma atomic emission spectroscopy (ICP-OES) measurements. These measurements showed that the ratio of conductivity to $\mathrm{Na}^{+}$concentration was higher in Instant Ocean solution as compared to pure $\mathrm{NaCl}$, which is due to the contribution of other ions to conductivity. The conductivity measurement showed the total ion concentration, but elemental analysis using ICP-OES proved algae grown in saline water prepared from Instant Ocean had higher sodium removal rates as compared to solution made from pure $\mathrm{NaCl}$ solution. This difference could be due the fact that Instant Ocean contains other ions at the same total mass of salt in solution, which promoted algal growth. The change in conductivity showed more salt removal by the $S$. sp. compared to $C$. vulgaris (Fig. 3b), but the ion measurements showed that $C$. vulgaris is better in the removal of sodium specifically than the $S$. sp.

In order to confirm the results of salt removal, algae ware separated from the solution by centrifuge, and it was re-suspended in DI water. Ion measurements of these samples showed $\mathrm{Na}^{+}$to be the most abundant ion in the biomass. By extrapolating the results obtained from $5 \mathrm{~mL}$ liquid sample to the total liquid volume of $250 \mathrm{~mL}$, removal of ca. $10 \%$ was observed within all samples. Comparing these results with the quantities of salts sequester because of the small amount of the biomass 


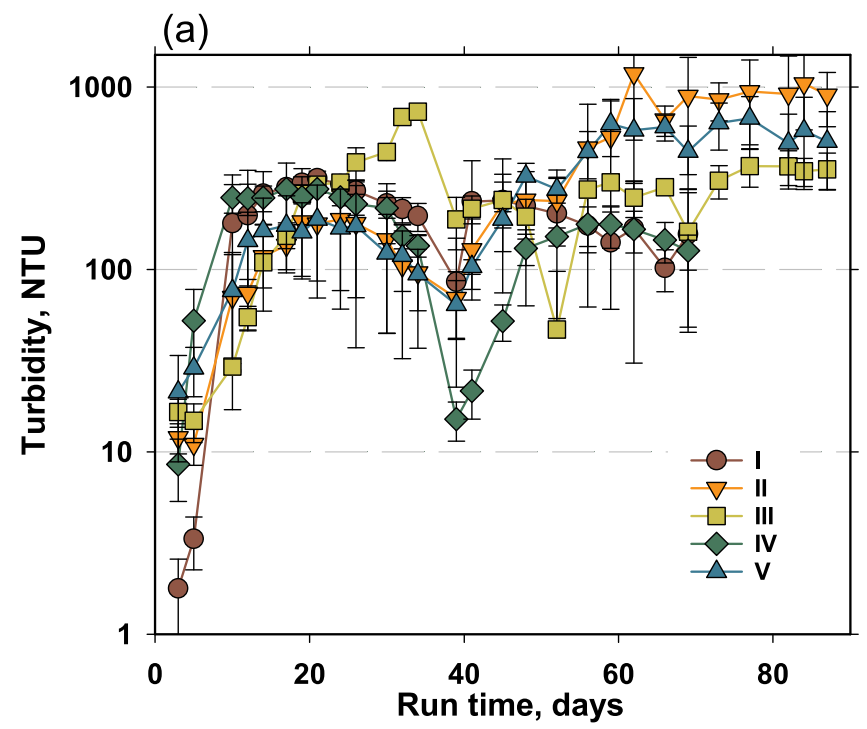

(b)

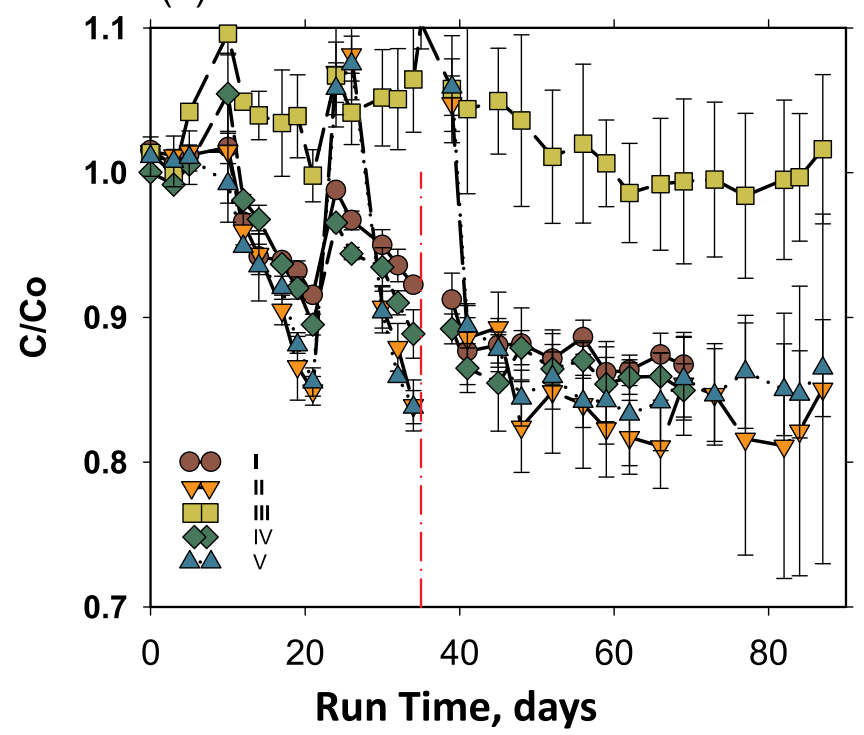

Fig. 5. Desalination using selected algae $S$. sp. and $C$. vulgaris regrowth tests based on changes in (a) turbidity, (b) salinity. Legend symbols stand I - S. sp., F/ 2 media, 4 g/L, II - S. sp., F/2 media, 4 g/L, III - S. sp., F/2 media, 20 g/L, IV - C. vulgaris, F/2 media, $4 \mathrm{~g} / \mathrm{L}, \mathrm{V}-\mathrm{C}$. vulgaris, BM, $4 \mathrm{~g} / \mathrm{L}$.

available in such small liquid volume. However, the result provided an additional proof of the salt removal and its uptake within the alga cells.

The distribution of ions found in both species is shown in Fig. S3. Sodium was the most abundant ion in both species followed by potassium. Barium, calcium, iron, phosphorus, sulfur and zinc are available in relatively high amounts. $S$. sp. showed higher tendency to retain sodium and potassium, which are the most abundant ions, however similar amounts were observed for the rest of the ions. The amount of sodium retained by the $S$. sp. was the same from solution based on Instant Ocean and pure $\mathrm{NaCl}$, while all the other ions were higher in Instant Ocean. The same behavior was observed in liquids containing $C$. vulgaris. On the other hand, using F/2 for growing $S$. sp. yielded higher sodium, potassium and phosphorus retention than the BM. Whereas for C. vulgaris using BM showed highest sodium and other major ions followed by F/2 and finally Alga-Gro.

\subsection{Strategies of algae-water separation}

Once bio-desalination process has occurred, efficient algae-water

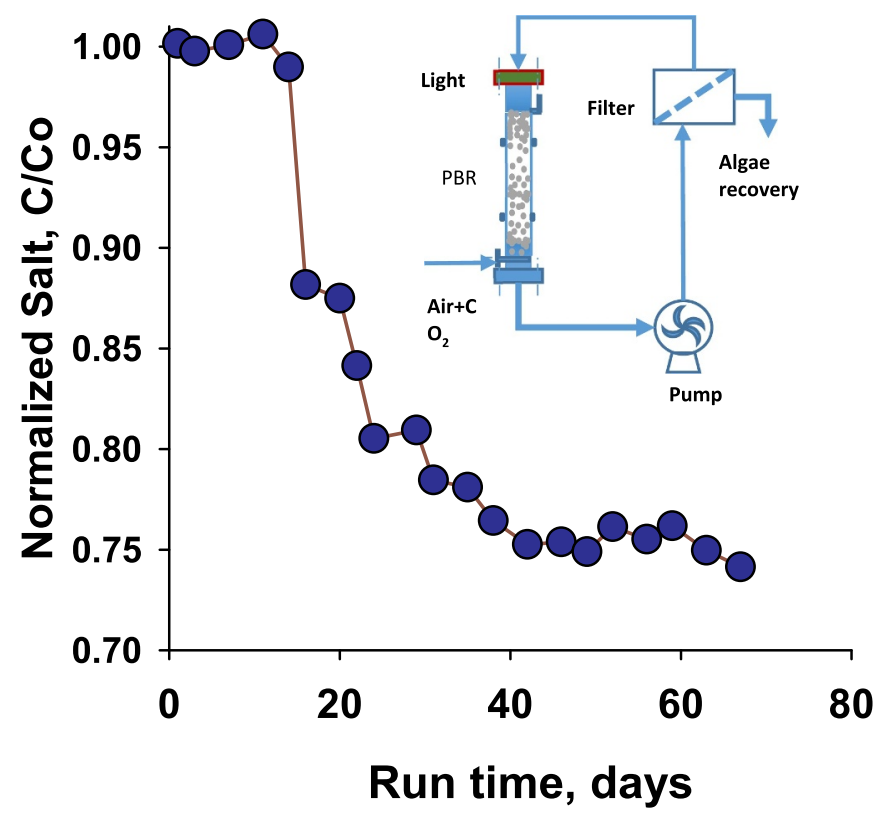

Fig. 6. Biodesalination performance of brackish water using $S$. sp. grown in a recycle pilot-scale recycled $\mathrm{PBR}$.

separation is needed. The downstream separation process of algae cells from the desalinated water without affecting the integrity of the cells and unintended release of absorbed salt back into the desalinated water could be a technical and an economical challenging bottleneck in the bio-desalination process [42-45]. The challenges of separating algae cell from aqueous suspensions come from due to little density difference to water, the microscale size with negatively charged surfaces that stabilizes cell suspensions and excess extracellular polymeric substances. To destabilize colloidal suspensions of algae coagulation, filtration and dissolved air floatation were tested. Coagulants such as polyelectrolytes or polyhydroxyl complexes have shown to have superior properties of attaching segments of algae to vacant sites of other algal particles forming a 3-D floc network.

\section{Conclusion and assessment integrated bio-desalination and biofuel process}

The provision of adequate water supply to match the word's growing demands has become a major challenge. The difficulties of the traditional source of water will continue to grow as we become more dependent on groundwater from steadily falling aquifers. In this paper we have presented exploratory study on the challenges and opportunities associated with the use of algae in reducing salinity of brackish water. The current physicochemical desalination technologies have negative impacts on climate, ocean salinity and other natural processes. The use of algae to remove salinity while providing necessary algal growth have much lower energy demand while the algae can be harvested for either to generate biofuel or source for protein. Biodesalination requires an efficient and a low-cost separation of algal cells from water (Table 1). Successful use of bio-desalination technology could ensure a sustainable supply of water for drinking and agricultural use at low in cost while producing valuable bio-fuel as a byproduct to supply energy for the desalination process.

A flowchart for algal screening for bio-desalination is presented in Fig. S7. The total energy for desalination of water can be reduced by making use of harvested algae for energy generation and integrating the process with conventional membrane desalination. The integration of bio-desalination with biofuel production could address the water-energy and has the potential to be a sustainable approach to reinventing drinking water (Fig. S7). The success of developing a biological 
Table 1

Summary of salinity reduction at end of desalination and algal removal.

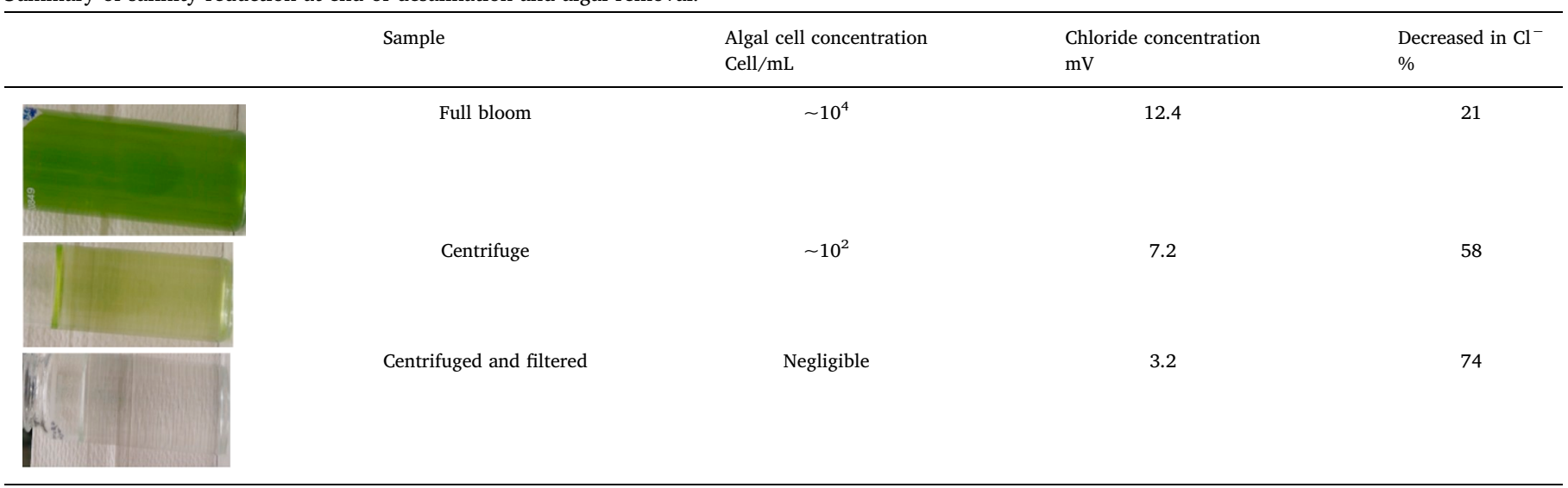

desalination depends on the selection of algal species that can grow in seawater, the optimization of salt-uptake, the separation of algae from the treated water in a sustainable manner.

Life cycle assessment of the integrated desalination system of algae bio-desalination preceded by reverse osmosis (RO) is necessary for a holistic assessment of the system. Experimental studies are essential to examine the effect of the bio-desalination on the organic matter concentration that could increase the potential for biofouling reverse osmosis membrane.

To design a realistic industrial facility, we extrapolated laboratory measurements and combined them with known processes developed for bio-fuel and desalination system. The potential salinity reductions were computed based on various scenarios and were used to select the process chain. In addition to the overall energetic balance of the production chain the impacts of the reduction of water salinity, further work is needed to the benefits of algal bio-fuel compared to diesel fuel, and issues of water quality related to large-scale algal growth.

This study revealed that the successive optimization of the bio-desalination process and the potential use of algae for desalination and biofuel resource could make this technology attractive and sustainable. The application of multiscale cascaded PBRs and continuous harvesting of the algae to sustain the high algae growth rate would increase the salt uptake. This technology could be used either for desalination of brackish water with lower salinity or as a pretreatment for seawater prior to reverse osmosis. Bio-desalination could be used for multiple purposes depending on the initial salt concentration. In a descending order with respect to salt concentration, the target applications of this technology are influent for conventional desalination, animal feed, irrigation, and drinking purposes, respectively. With further development such as multistage operation, this technology could be an environmentally sustainable method that serves multiple purposes to provide water that is safe, appropriate for agricultural use, and produce biofuel. As is the case in other biotechnological processes, bio-desalination requires efficient separation of algae from the water. Floatation and filtration are suitable methods to remove up to $99 \%$ of algae. However, the presence of algal biomass requires an integrated bio-desalination process which is likely to build on knowledge of both algal bioreactors and innovative water treatment processes.

\section{Acknowledgement}

The research received seed funding through the EPA internal competition "Pathfinder Innovation Projects" challenge in pursuit of highrisk, high-reward research ideas. We thank Tom Deinlein for building the laboratory PBRs. AAH was a post-doctoral research fellow at the National Risk Management Research Laboratory administered by the Oak Ridge Institute for Science and Education through an interagency agreement between the U.S. Department of Energy and the U.S. Environmental Protection Agency.

\section{Disclaimer}

The US EPA, Office of Research and Development funded and managed this research described herein. It has been subjected to the Agency's Administrative review and has been approved for external publication. Any opinion expressed in this paper are those of the authors and do not reflect the views of the U.S. EPA. Approval does not signify that the contents reflect the views of the Agency, nor does mention of trade names or commercial products constitute endorsement or recommendation for use.

\section{Appendix A. Supplementary data}

Supplementary data to this article can be found online at https:// doi.org/10.1016/j.desal.2019.05.002.

\section{References}

[1] R.F. Service, Desalination freshens up, Science 313 (2006) 1088-1090.

[2] United Nations, Role of desalination in addressing water scarcity, ESCWA Water Development Report 3, United Nation, New York, 2009.

[3] United Nations Development Programme (UNDP), Beyond scarcity: Power, poverty and the global water crisis, Human Development Report 2006, United Nations Development Programme (UNDP), New York, NY, 2006.

[4] M. Elimelech, W.A. Phillip, The future of seawater desalination: energy, technology, and the environment, Science 333 (2011) 712-717.

[5] S. Burn, M. Hoang, D. Zarzo, F. Olewniak, E. Campos, B. Bolto, O. Barron, Desalination techniques - a review of the opportunities for desalination in agriculture, Desalination 364 (2015) 2-16.

[6] M.D. Stuber, C. Sullivan, S.A. Kirk, J.A. Farrand, P.V. Schillaci, B.D. Fojtasek, A.H. Mandell, Pilot demonstration of concentrated solar-powered desalination of subsurface agricultural drainage water and other brackish groundwater sources, Desalination 355 (2015) 186-196.

[7] G.L. Meerganz von Medeazza, "Direct" and socially-induced environmental impacts of desalination, Desalination 185 (2005) 57-70.

[8] G. Raluy, L. Serra, J. Uche, Life cycle assessment of MSF, MED and RO desalination technologies, Energy 31 (2006) 2361-2372.

[9] N.P. Yensen, Halophyte uses for the twenty-first century, in: M.A. Khan, D.J. Weber (Eds.), Ecophysiology of High Salinity Tolerant Plants, Springer Netherlands, Dordrecht, 2006, pp. 367-396.

[10] FAO, New dimensions of water security, Food and Agriculture Organization of the United Nations, Rome, Italy, 2000.

[11] M. Omar, D. Balla, Drainage water purification in saline detention ponds with duckweeds, in: I.-C.T.I.C.o.I.a. Drainage (Ed.), 23rd European Regional Conference, "Progress in Managing Water for Food and Rural Development" Lviv, Ukraine, 2009.

[12] A. El-Sayed, M. El-Fouly, E. Abou El-Nour, Immobilized microalga Scenedesmus sp. for biological desalination of Red Sea water: I. Effect on growth, Nat. Sci. 8 (2010) 69-76.

[13] M.A. Khan, D.J. Weber, Ecophysiology of High Salinity Tolerant Plants, Springer Science \& Business Media, 2006.

[14] X. Gan, G. Shen, B. Xin, M. Li, Simultaneous biological desalination and lipid 
production by Scenedesmus obliquus cultured with brackish water, Desalination 400 (2016) 1-6.

[15] Z. Yao, C. Ying, J. Lu, Q. Lai, K. Zhou, H. Wang, L. Chen, Removal of K+, Na + $\mathrm{Ca} 2+$, and $\mathrm{Mg} 2+$ from saline-alkaline water using the microalga Scenedesmus obliquus, Chin. J. Oceanol. Limnol. 31 (2013) 1248-1256.

[16] S. Panwichian, D. Kantachote, B. Wittayaweerasak, M. Mallavarapu, Isolation of Purple Nonsulfur Bacteria for the Removal of Heavy Metals and Sodium From Contaminated Shrimp Ponds, (2010).

[17] K. Minas, E. Karunakaran, T. Bond, C. Gandy, A. Honsbein, M. Madsen, J. Amezaga, A. Amtmann, M.R. Templeton, C.A. Biggs, L. Lawton, Biodesalination: an emerging technology for targeted removal of $\mathrm{Na}+$ and $\mathrm{Cl}-$ from seawater by cyanobacteria, Desalin. Water Treat. 55 (2015) 2647-2668.

[18] A.M. Hebert, R.H. Vreeland, Phenotypic comparison of halotolerant bacteria: Halomonas halodurans sp. nov., nom. rev., comb. nov, Int. J. Syst. Evol. Microbiol. 37 (1987) 347-350.

[19] E.N.M.H. A., E.S.F.A.G. H., E.H.O. M., Desalination using algae ponds under nature Egyptian conditions, J. Water Resour. Ocean Sci. 3 (2014) 69-73.

[20] R. Barghbani, K. Rezaei, A. Javanshir, Investigating the effects of several parameters on the growth of Chlorella vulgaris using Taguchi's experimental approach, Int. J. Biotechnol. Wellness Ind. 1 (2012) 128.

[21] A. Aly Hassan, G. Sorial, Biological treatment of benzene in a controlled trickle bed air biofilter, Chemosphere 75 (2009) 1315-1321.

[22] A. Aly Hassan, G.A. Sorial, n-Hexane biodegradation in trickle bed air biofilters, Water Air Soil Pollut. Focus 8 (2008) 287-296.

[23] J.D. Pfaff, C.A. Brockhoff, J.W. O'Dell, U.S. Environmental Protection Agency (Ed.), Method 300.0: The Determination of Inorganic Anions in Water by Ion Chromatography, 1989.

[24] R.G. Jones, Measurements of the electrical conductivity of water, IEE Proc. Sci. Meas. Technol. 149 (2002) 320-322.

[25] E. Blumwald, R.J. Mehlhorn, L. Packer, Ionic osmoregulation during salt adaptation of the cyanobacterium Synechococcus 6311, Plant Physiol. 73 (1983) 377-380.

[26] J.M. Amezaga, A. Amtmann, C.A. Biggs, T. Bond, C.J. Gandy, A. Honsbein, E. Karunakaran, L. Lawton, M.A. Madsen, K. Minas, M.R. Templeton, Biodesalination: a case study for applications of photosynthetic bacteria in water treatment, Plant Physiol. 164 (2014) 1661-1676.

[27] K. Wiangnon, W. Raksajit, A. Incharoensakdi, Presence of a Na +-stimulated P-type ATPase in the plasma membrane of the alkaliphilic halotolerant cyanobacterium Aphanothece halophytica, FEMS Microbiol. Lett. 270 (2007) 139-145.

[28] R.R. Guillard, Culture of phytoplankton for feeding marine invertebrates, Culture of Marine Invertebrate Animals, Springer, 1975, pp. 29-60.

[29] S.K. Apte, J. Thomas, Sodium transport in filamentous nitrogen fixing cyanobacteria, J. Biosci. 5 (1983) 225-233.
[30] E.S. Maeso, F.F. Piñas, M.G. Gonzalez, E.F. Valiente, Sodium requirement for photosynthesis and its relationship with dinitrogen fixation and the external $\mathrm{CO}_{2}$ concentration in cyanobacteria, Plant Physiol. 85 (1987) 585-587.

[31] G.S. Espie, A.G. Miller, D.T. Canvin, Characterization of the $\mathrm{Na}+$-requirement in cyanobacterial photosynthesis, Plant Physiol. 88 (1988) 757-763.

[32] S. Bhargava, R.K. Saxena, P.K. Pandey, P.S. Bisen, Mutational engineering of the cyanobacterium Nostoc muscorum for resistance to growth-inhibitory action of LiCl and NaCl, Curr. Microbiol. 47 (2003) 0005-0011.

[33] M. Fisher, I. Gokhman, U. Pick, A. Zamir, A structurally novel transferrin-like protein accumulates in the plasma membrane of the unicellular green alga Dunaliella salina grown in high salinities, J. Biol. Chem. 272 (1997) 1565-1570.

[34] I. Ahmad, J.A. Hellebust, Osmoregulation in the extremely euryhaline marine micro-alga Chlorella autotrophica, Plant Physiol. 74 (1984) 1010-1015.

[35] K. Chojnacka, Biosorption and bioaccumulation - the prospects for practical applications, Environ. Int. 36 (2010) 299-307.

[36] L. Velásquez, J. Dussan, Biosorption and bioaccumulation of heavy metals on dead and living biomass of Bacillus sphaericus, J. Hazard. Mater. 167 (2009) 713-716.

[37] K. Vijayaraghavan, Y.-S. Yun, Bacterial biosorbents and biosorption, Biotechnol. Adv. 26 (2008) 266-291.

[38] N. Rangsayatorn, E.S. Upatham, M. Kruatrachue, P. Pokethitiyook, G.R. Lanza, Phytoremediation potential of Spirulina (Arthrospira) platensis: biosorption and toxicity studies of cadmium, Environ. Pollut. 119 (2002) 45-53.

[39] V.K. Gupta, A. Rastogi, Biosorption of hexavalent chromium by raw and acidtreated green alga Oedogonium hatei from aqueous solutions, J. Hazard. Mater. 163 (2009) 396-402.

[40] V.K. Gupta, A. Rastogi, A. Nayak, Biosorption of nickel onto treated alga (Oedogonium hatei): application of isotherm and kinetic models, J. Colloid Interface Sci. 342 (2010) 533-539.

[41] V.K. Gupta, A. Rastogi, Biosorption of lead from aqueous solutions by green algae Spirogyra species: kinetics and equilibrium studies, J. Hazard. Mater. 152 (2008) 407-414.

[42] A. Schlesinger, D. Eisenstadt, A. Bar-Gil, H. Carmely, S. Einbinder, J. Gressel, Inexpensive non-toxic flocculation of microalgae contradicts theories; overcoming a major hurdle to bulk algal production, Biotechnol. Adv. 30 (2012) 1023-1030.

[43] M.K. Lam, K.T. Lee, Microalgae biofuels: a critical review of issues, problems and the way forward, Biotechnol. Adv. 30 (2012) 673-690.

[44] E.J. Olguín, Dual purpose microalgae-bacteria-based systems that treat wastewater and produce biodiesel and chemical products within a biorefinery, Biotechnol. Adv. 30 (2012) 1031-1046.

[45] N. Uduman, Y. Qi, M.K. Danquah, A.F. Hoadley, Marine microalgae flocculation and focused beam reflectance measurement, Chem. Eng. J. 162 (2010) 935-940. 